\title{
Optimal placement of SVCs \& IPFCs in an Electrical Power System
}

\author{
M.V.Ramesh, Dr. V.C. Veera Reddy \\ Associate Professor, Priyadarashini college of Engineering \& technology Nellore, AP, India \\ Professor \& Head of the Dept, EEE S.V.University, Tirupathi, AP, India
}

\begin{abstract}
To maintain voltage \& power losses are within the acceptable limits at normal, over load and contingency conditions different types of techniques are used in power system. FACTS devices are more predominated than compared to other techniques. But, the cost of the FACTS devices are costlier, were optimally placed using a heuristic method. In this paper SVCs \& IPFCs are optimally placed in different load \& contingency conditions using PSO. The simulations are performed on an IEEE 30-bus system and results are presented.
\end{abstract}

Keywords: SVC, IPFC, over load, Contingency, Power loss, Voltage profile, PSO, IEEE 30 bus.

\section{INTRODUCTION}

The problem of optimal location of FACTS devices is modeled as an optimization technique. The aim is to find the maximum amount of power that the power system is able to supply without overloading the lines and acceptable voltage limits. And also to maintain voltage \& power losses are within the acceptable limits at normal, over load and contingency conditions different types of techniques are used in power system. FACTS devices are more predominated than compared to other techniques.

In normal operating conditions, the power system losses are the minimum and voltages are prescribed limits. The power system may be collapse due to the following reasons such as outage of a generating unit or of a line, sudden increasing or decreasing of the power demand. Most of the times, the system may remains as it original state within the limitations of voltage \& power. But sometimes, it does not become to its original state. This phenomenon is called contingency. In previews, the research engineers are found an optimal location of FACTS devices like SVC, TCSC, and UPFC at different load conditions $(1,3,4)$.

In this paper, a new research method is implemented on an optimal location of SVC and IPFC in normal, over load and as well as contingency conditions (2). In recent decades, different types of biological optimization techniques like GA, PSO, AC, EP,DE etc are implemented. In this research, DE technique is used to optimal location of devices. The simulations are performed on a modified IEEE 30 bus system and results are presented at different contingency conditions.

Problem Formulation:

The power flow through any transmission line can be obtained by using the equation

$P_{i j}=\left(V_{i} V_{j} \sin \theta_{i j}\right) / X_{i j}$

$\mathrm{Q}_{\mathrm{ijj}}=\mathrm{V}_{\mathrm{i}}\left(\mathrm{V}_{\mathrm{i}}-\mathrm{V}_{\mathrm{j}} \cos \theta_{\mathrm{ij}}\right) / \mathrm{X}_{\mathrm{ij}}$

Where $P_{i j}$ is the active power flow through the transmission line $i$ to $j, Q_{i j}$ is the reactive power flow through the transmission line $\mathrm{i}$ to $\mathrm{j}, \mathrm{V}_{\mathrm{i}}, \mathrm{V}_{\mathrm{j}}$ are the bus voltage magnitudes, $\mathrm{X}_{\mathrm{ij}}$ is the reactance of the transmission line $\& \theta_{\mathrm{ij}}$ is the phase angle between $\mathrm{i}$ and $\mathrm{j}$ buses.

The power flow through the transmission line can be controlled by changing any one of the above mentioned parameters using different types of FACTS devices. In this paper two types of FACTS devices are used one is SVC, which is the basic model of shunt type of FACTS device and other is IPFC, which is latest version of FACTS device.

\section{Mathematical models of FACTS devices:}

The main aim of this objective is to perform a best utilization of the existing transmission lines in normal conditions by an optimal location of FACTS devices in a network.

\section{STATIC VAR COMPENSATOR}

The Static var compensator is a shunt type of FACTS devices, which absorbs or injects reactive power at which it is connected. The size of the SVC is depends on the rating of current and reactive power injected into the bus. 


\section{INTERLINE POWER FLOW CONTROLLER}

The IPFC is a series-series type of FACTS device, which is used to exchange reactive powers in between two or more transmission lines those are connected to the same bus.

\section{Partial Swarm Optimization:}

The step by step procedure for the proposed optimal placement of SVC and IPFC devices using PSO is given below:

Step 1: The number of devices to be placed is declared. The load flow is performed.

Step 2: The initial population of individuals is created satisfying the SVC \& IPFC constraints.

Step 3: For each individual in the population, the fitness function is evaluated after running the load flow.

Step 4: The velocity is updated and new population is created.

Step 5: If maximum iteration number is reached, then go to next step else go to step 3.

Step 6: Print the best results.

Step 7: stop

\section{A CASE STUDY}

The PSO based optimal placement of SVCs \& IPFCs was implemented using MATLAB 7.5. The system tested on an IEEE 30-bus system.

The following parameters are used for PSO based optimal location of FACTS devices.

- Population $=50$

- Maximum iterations $=200$

- $\mathrm{Wmax}=0.9$ and $\mathrm{Wmin}=0.4$

- Acceleration constants $\mathrm{C} 1=1.4$ and $\mathrm{C} 2=1.4$

The type of the device, the location and rating of the devices are found in normal, over load and contingency conditions. The voltages at each bus, total power losses, the location of different types of FACTS devices and its ratings are mentioned.

The locations of SVCs are considered at all the buses and three numbers of IPFCs are considered in IEEE 30 bus system.

\begin{tabular}{|l|c|l|}
\hline & $\begin{array}{l}\text { Before compensation } \\
\text { the real power losses }\end{array}$ & $\begin{array}{l}\text { After compensation } \\
\text { the real power losses }\end{array}$ \\
\hline Normal load conditions & 17.5985 & 17.2631 \\
\hline Different load onditions & 55.8193 & 52.3394 \\
\hline $\begin{array}{l}\text { Contingency conditions } \\
\text { (between 21 \& 22) }\end{array}$ & 55.8382 & 51.6348 \\
\hline
\end{tabular}
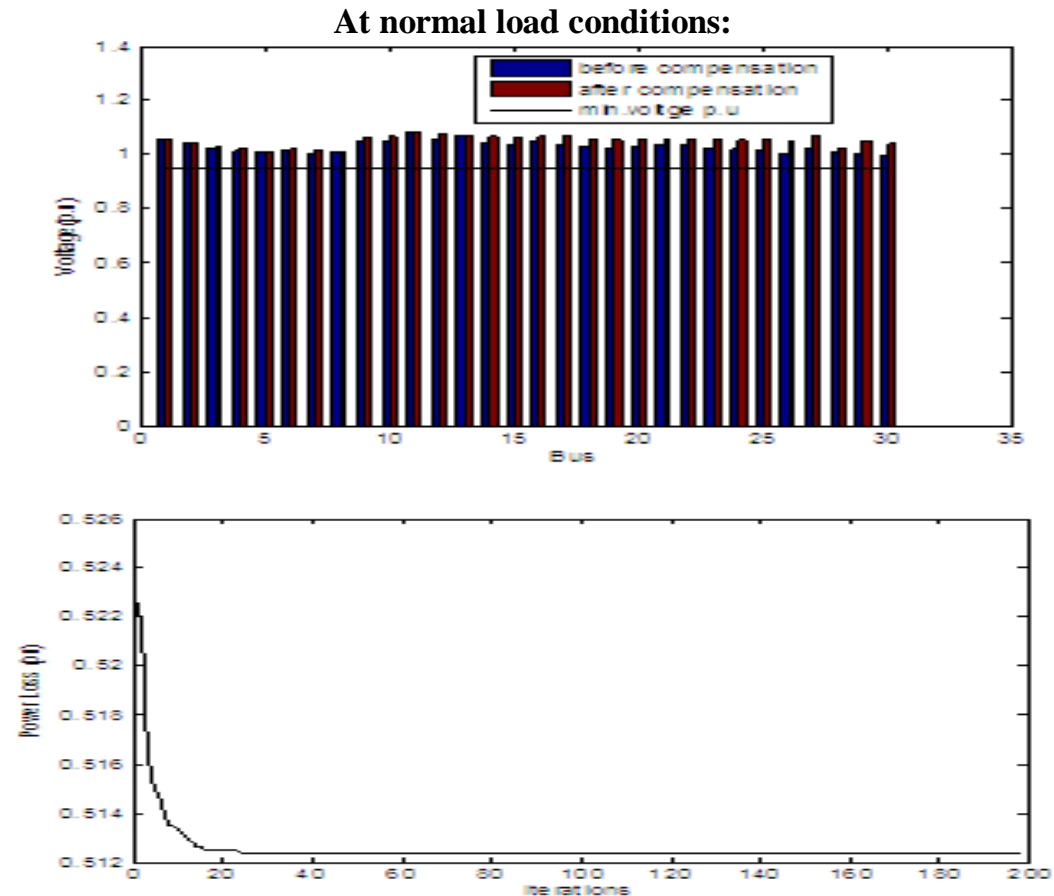

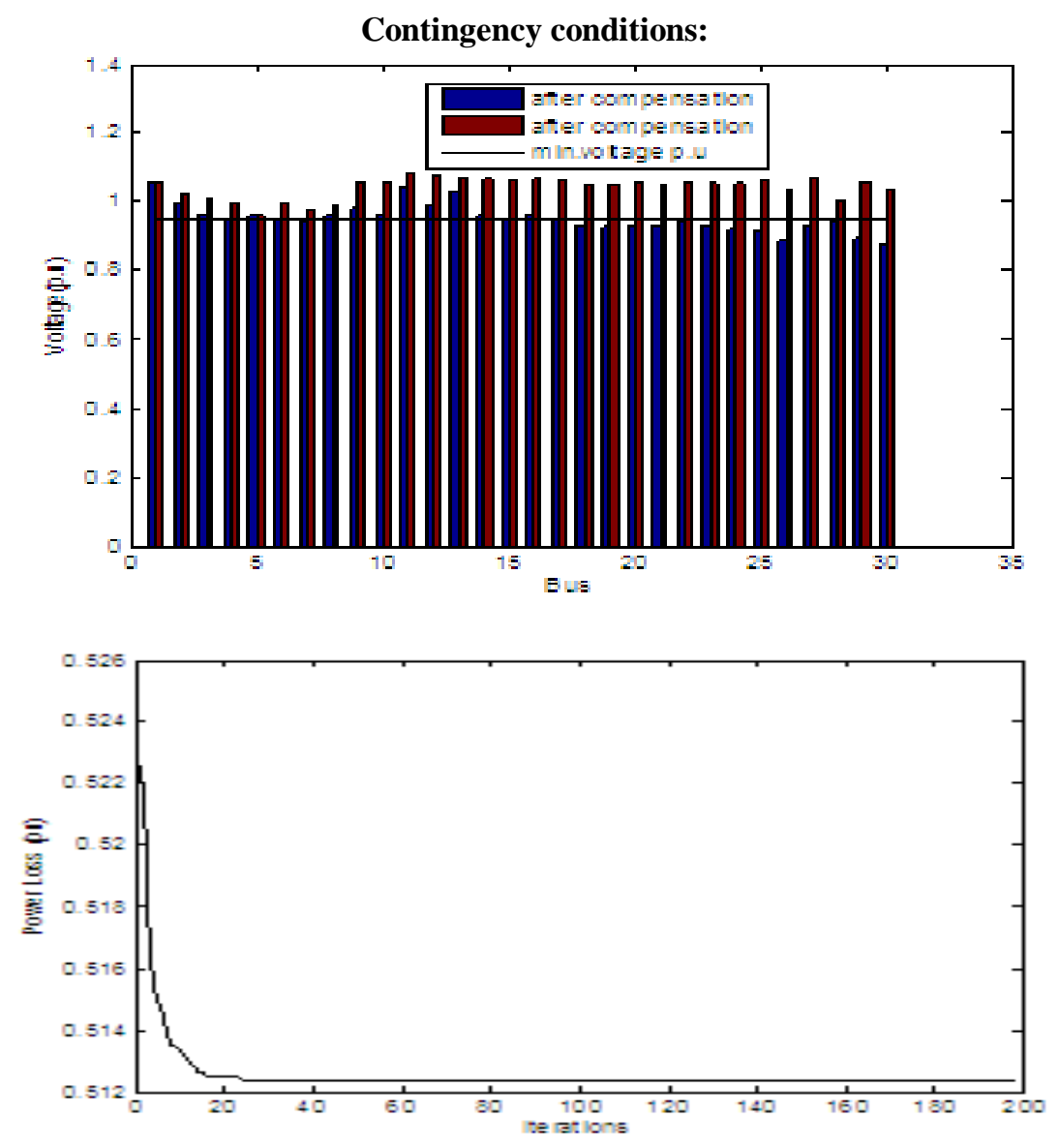

At different conditions:
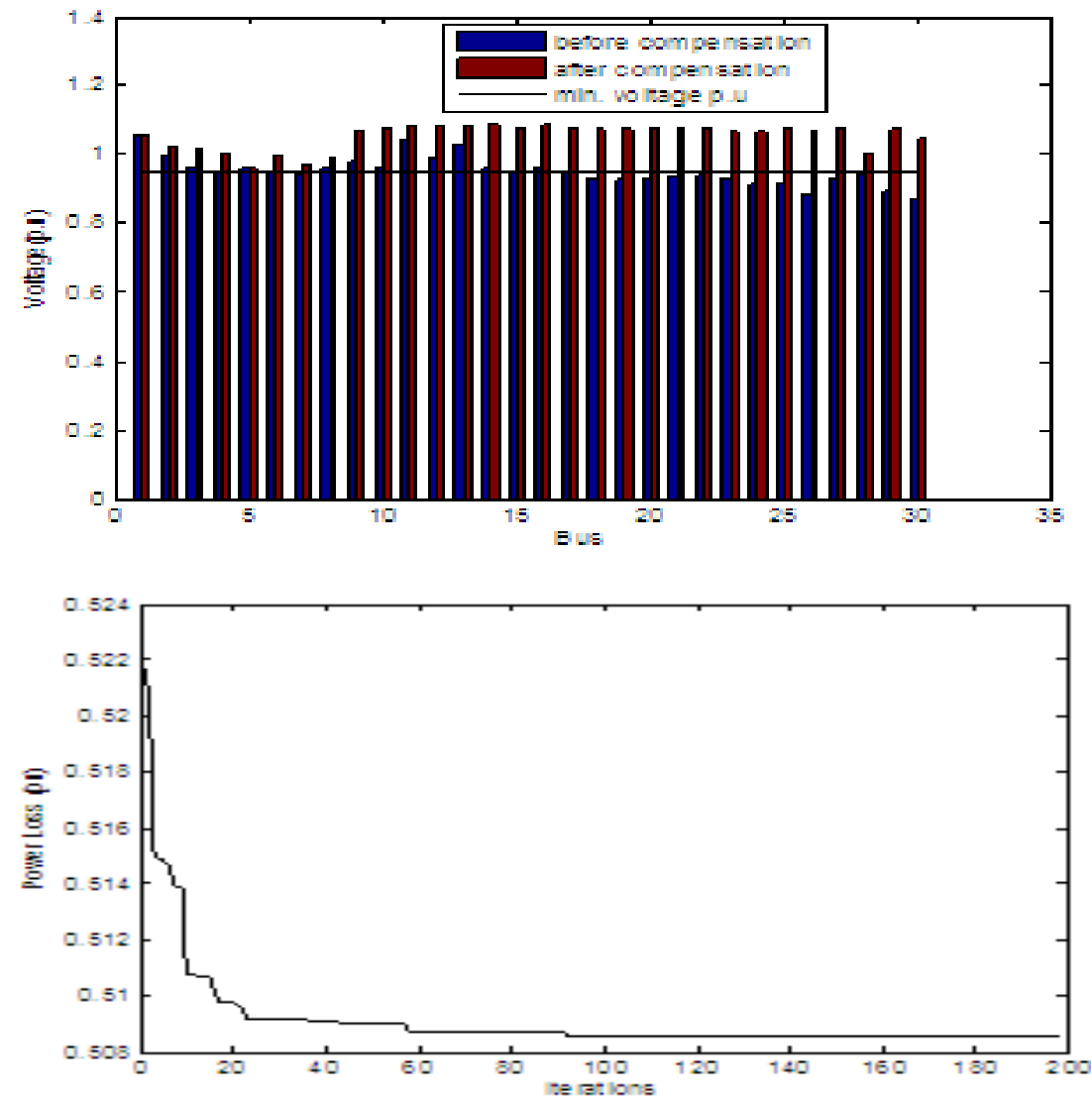
Optimal placement of SVCs \& IPFCs in an Electrical Power System

Optimal location of SVCs \& IPFCs in different conditions and its ratings in Mvar:

\begin{tabular}{|c|c|c|c|}
\hline $\begin{array}{l}\text { Optimal location of } \\
\text { SVC at each bus }\end{array}$ & $\begin{array}{l}\text { Atnormal } \\
\text { conditions }\end{array}$ & $\begin{array}{l}\text { At } 1.6 \text { base load at } \\
\text { each bus conditions }\end{array}$ & $\begin{array}{l}\text { Contingency } \\
\text { conditions }\end{array}$ \\
\hline 1 & 4 & 8 & 4 \\
\hline 2 & 2 & 12 & 2 \\
\hline 3 & 0 & 12 & 8 \\
\hline 4 & 14 & 13 & 9 \\
\hline 5 & 9 & 12 & 0 \\
\hline 6 & 1 & 14 & 7 \\
\hline 7 & 13 & 8 & 18 \\
\hline 8 & 0 & 0 & 3 \\
\hline 9 & 0 & 5 & 6 \\
\hline 10 & 9 & 16 & 9 \\
\hline 11 & 0 & 2 & 6 \\
\hline 12 & 2 & 0 & 8 \\
\hline 13 & 1 & 0 & 8 \\
\hline 14 & 3 & 14 & 7 \\
\hline 15 & 2 & 4 & 8 \\
\hline 16 & 2 & 15 & 6 \\
\hline 17 & 8 & 2 & 13 \\
\hline 18 & 3 & 7 & 1 \\
\hline 19 & 0 & 8 & 4 \\
\hline 20 & 3 & 4 & 7 \\
\hline 21 & 2 & 14 & 14 \\
\hline 22 & 6 & 17 & 2 \\
\hline 23 & 2 & 0 & 2 \\
\hline 24 & 6 & 11 & 12 \\
\hline 25 & 0 & 2 & 6 \\
\hline 26 & 2 & 6 & 0 \\
\hline 27 & 4 & 4 & 7 \\
\hline 28 & 0 & 0 & 4 \\
\hline 29 & 1 & 10 & $\bar{A}$ \\
\hline 30 & 2 & 1 & 3 \\
\hline
\end{tabular}

\begin{tabular}{|c|c|c|c|}
\hline $\begin{array}{l}\text { Optimal location of } \\
\text { IPFC (between the ines) }\end{array}$ & $\begin{array}{l}\text { Atnormal load } \\
\text { conditions }\end{array}$ & $\begin{array}{l}\text { At 1.6 base load at } \\
\text { each bus conditions }\end{array}$ & $\begin{array}{l}\text { At ontingency } \\
\text { conditions }\end{array}$ \\
\hline $2-5 \& 2-6$ & 4.0771 & 5.9905 & 5.2694 \\
\hline $6-8 \& 6-9$ & 2.2929 & 0.8277 & 8.2119 \\
\hline $12-13 \& 12-15$ & 4.9054 & 6.5346 & 13.4279 \\
\hline
\end{tabular}

By comparing the above cases, the total power losses of the system are reduced and voltage levels are improved by the optimal location of SVC \& IPFC type of FACTS devices in an electrical power network.

\section{CONCLUSION}

In this paper, the optimal location of IPFC and SVC are studied at normal load conditions and various parameters such as voltage profile and real and reactive power flow in transmission lines are investigated using PSO. In this paper, we have proposed a PSO algorithm to place a combination of both SVC and IPFC devices. The future scope of this paper is a complete cost benefit analysis has to be carried out to justify the economic viability of the SVC and IPFC using different combination of optimization techniques. 


\section{REFERENCES}

[1]. S.Gerbex, R.cherkaoui, and A.J.Germond, "Optimal Allocation of FACTS Devices by Using MultiObjective Optimal Power Flow and Genetic Algorithms”. IEEE trans.power system, vol.16, pp.537-544, August 2001.

[2]. M.V.Ramesh, Dr. V.C. Veera Reddy “ Optimal Allocationof FACTS Devices in Different Over Load Conditions" International Journal of Electrical Engineering \& Technology, volume 4, issue 1, Jan-Feb 2013, pp-208-222.

[3]. L.J.Cai, I.Erlich, G.Stamtsis "Optimal Choice and Allocation of FACTS Devices in Deregulated Electricity Market using Genetic Algorithms" IEEE transactions on 2004.

[4]. H.R.Bahaee, M.Jannati, B.Vahidi, S.H.Hosseinnian, H.Rastager: Improvement of voltage stability and reduce power system losses by optimal GA-base allocation of Multi-Type FACTS devices. The $11^{\text {th }}$ international IEEE conference on May 2008,OPTIM 2008.

[5]. K.Sundareswaran, P.Bharathram, M.siddharth, Vaishavi.G, Nitin Anand Srivastava, Harish Sharma: Voltage Profile enhancement through optimal placement of FACTS devices using Queen Bee Assisted GA. The $3^{\text {rd }}$ international conference on power systems, Kharagapur, December 2009.

[6]. S Teerathana, A. Yokoyama, "An Optimal Power Flow Control Method of Power System using Interline Power Flow Controller (IPFC)”, IEEE Transactions on Power Delivery, Vol. 23,pp. 343-346, Aug. 2004.

[7]. P. Subburaj, N. Sudha, K. Rajeswari, K. Ramar,and L. Ganesan, "Optimum Reactive Power Dispatch Using Genetic Algorithm,” Academic Open Internet Journal, Vol.21, 2007, p6

[8]. B.Geethalakshmi, T. Hajmunisa and P. Dhananjayan, "Dynamic characteristics analysis of SSSC based on 48 pulse inverter", The $8^{\text {th }}$ International Power Engineering Conference (IPEC) pp. 550-554, May 2007.

[9]. A.V.Naresh Babu, S.Sivanagaraju, Ch.Padmanabharaju and T.Ramana "Multi-Line Power Flow Control using Interline Power Flow Controller (IPFC) in Power" Transmission Systems International Journal of Electrical and Electronics Engineering 4:7 2010

\section{Authors:}

\section{M.V.Ramesh:}

B.Tech(EEE) from S.V.H.College of Engineering, Machilipatnam in 2000. M.Tech in Power Electronics from J.N.T.University, Hyderabad (Autonomous) in 2005. Pursuing PhD in J.N.T. University, Hyderabad.

\section{Dr. V.C.Veera Reddy:}

B.Tech(EEE) from J.N.T. University in 1979. M.Tech in power systems \& operation control from S.V. University in 1981. Completed PhD from S.V. University in 1999. 